\title{
Handover Adaptations for Load Balancing Scheme in Macrocell/Femtocell LTE Network
}

\author{
Azita Laily Yusof, Norsuzila Ya'acob, and Mohd Tarmizi Ali
}

\begin{abstract}
In the purpose of offering extensively higher data rates, higher systems throughput and lower latency, the femtocell systems in 3GPP LTE system has premeditate. In a large number of femtocells, there are too many prehandover and unnecessary handover processes frequently among femtocells may occur. Also, call failure due to handover may increase when the mobile moves from one serving cell to another cell. High number of switching load will occur due to the ping-pong effect. Handover procedures for existing networks are needed to support the macrocell/femtocell integrated network. This paper proposes a modified handover procedure between macrocell and femtocell network. A handover algorithm is proposed based on Received Signal Strength (RSS) and speed of the UE to improve the handovers between the macrocell and femtocell in LTE network. The result shows that the unnecessary handover and handover failure can be optimized using modified handover in this macrocell and femtocell integrated network. Thus, the deployment of femtocell can increase the handover performance as well as offloading the macrocell traffic.
\end{abstract}

Index Terms-Handover, macrocell, femtocell, receive signal strength, velocity, dropcall

\section{INTRODUCTION}

Mobile data communications has undergone significant evolution in recent years. The introduction of High Speed Downlink Packet Access (HSDPA) enabled mobile broadband internet for the first time. This resulted in an exponential increase in the traffic volume of the mobile data. In the future, it is expected that there will be more mobile data demand than there has been before. According to Nokia Siemens Networks and Ericsson, it is estimated that the data usage rate will increase 1000 percent from 2010 to 2020 [1].

The rapidly increasing mobile data traffic has resulted in a major challenge for the operators. Data volumes are growing at a rate that exceeds the operators' ability to increase capacity. Capacity growth typically comes from growth in the number of sites, increased spectrum resources and enhancement of radio technologies.

which some of the data traffic is offloaded onto other smaller networks using microcells, picocells, femtocells and

Manuscript received July 9, 2013; revised September 10, 2013. This work was supported by the e-Science grant no. 01-01-01-SF0407 funded by the Ministry of Science, Technology and Innovation and Faculty of Electrical Engineering, Universiti Teknologi MARA.

Azita Laily Yusof is with the University of Technology MARA, 40450 Shah Alam, Selangor, Malaysia (e-mail: laily012001@yahoo.com).

Norsuzila Ya'acob was with the Teknologi MARA University, 40450 Shah Alam, Selangor, Malaysia (e-mail: norsuzilayaacob@yahoo.com).

Mohd Tarmizi Ali is with the Electrical Engineering Department, University of Technology MARA, 40450 Shah Alam, Selangor, Malaysia (e-mail: mizi732002@yahoo.com).
Wi-Fi access points. It is expected that the deployment of heterogeneous networks fulfills the expected future data demands [1]-[4]. In a cellular network, efficient allocation of the channels to each cell is needed due to limited bandwidth. This problem becomes even worse when some cells in the system are congested while others are not.

Therefore, this causes a hotspot problem in which the quality of service in congested cells is degraded by a considerable amount. It is well known that the hot spot problem can be resolved by dynamically balancing the load of the hot spot cells in cellular networks. To overcome the hotspot problem, the allocation of the users to the base stations should be guided by the load balancing principle [5]-[6]. By using the load balancing principle, it is possible to divide workload over the base stations as evenly as possible, thus fulfilling the target of minimizing the mean delay in the system.

This paper addresses the load balancing problem for heterogeneous wireless networks. These networks contain different types of cells in which each cell may have different characteristics. In general, these cells are divided into macrocells and femtocells. The macrocells are similar to the conventional base stations that we use in today's networks. They provide the basic coverage to the whole cell area. The rest of this paper is organized into four sections. Sections I give an overview of traffic offload in femtocell heterogeneous networks. The theoretical background that covers some relevant concepts related to the research topic is presented in Section II. In Section III, we introduce simulation model and discuss several parameters that proposed for this scheme. Results and discussion are explaining details in Section IV. Finally, in the last section, conclusions are drawn and future works for this research problem are also proposed.

\section{THEORETICAL BACKGROUND}

Femtocells are consumer deployable base stations that utilize the broadband connection of the consumer as the backhaul. They are suitable for indoor locations such as homes and offices (enterprise). Their transmit power is limited to $23 \mathrm{dBm}$. Therefore, a single femtocell can serve only a few users. However, a network of femtos can be used to cover larger areas such as an enterprise. An enterprise or public access femtocell has the functional equivalency of a picocell. In a traditional cellular network, all of the traffic to and from mobile phones and mobile internet devices travel from the device to a cell site that is typically a fraction of mile away.

However, in heterogeneous networks either a macrocell or a femtocell carries the traffic from the phone to the operator 
or another internet destination. The effect of traffic offload is that it results in a significant reduction of total traffic travelling over wide area radio networks of the operators. In addition, it also benefits consumers as it offers a higher bandwidth for mobile data connection. Femtocells are deployed at a wireless subscriber's home and the consumer attaches it to his or her broadband connection. Traffic then flows over the air to the femtocell and then over the internet to the operator's core network, and/or to other internet destinations.

One of the key advantages of using a femtocell is that the traffic generated by femtocells will not be carried by the macrocells. As a result, users in the macrocell have a better experience because of reduction in the number of users who compete for resources. Thus, using femtocells gives a dual benefit by reducing the traffic in the macro network and providing a strong signal to indoor users. Although introducing femtocells can give a significant improvement on user experience it has its own set of challenges. The major challenge comes from unplanned deployment of femtocells. This results in load balancing between femtocells and macrocell on both uplink and downlink. So, there is a need for efficient interference management techniques in heterogeneous networks.

\section{Simulation Model}

In order to evaluate the performance of the modified algorithm, a framework has been built using MATLAB software with few assumptions. The UE moves randomly with the constant speed and for each time period, the traffic is characteristic by the arrival of new calls in each femtocell by the transitions probability of macro/femto handoff calls. The arrival process of new call is assumed to be Poisson with negative exponential durations.

For the algorithm development, firstly we have to generate call parameter, BS parameter and UE parameter. The simulation model is develop using $70 \mathrm{UE}, 259$ hexagonal of macrocell and 60 of femtocell where each femtocell overlay the macrocell as shown in Fig. 1. Macrocell and femtocell are set to $10 \mathrm{~km}$ and $5 \mathrm{~km}$ in radius, respectively. Then we allocate resources for every BSc generated. When resource in femtocell is not available, UE can be temporarily connected to the macrocell if there is a free channel. But once a UE is connected to a macrocell, it will only be attached to macrocell BSs. Channel will be release by a UE after call is finished.

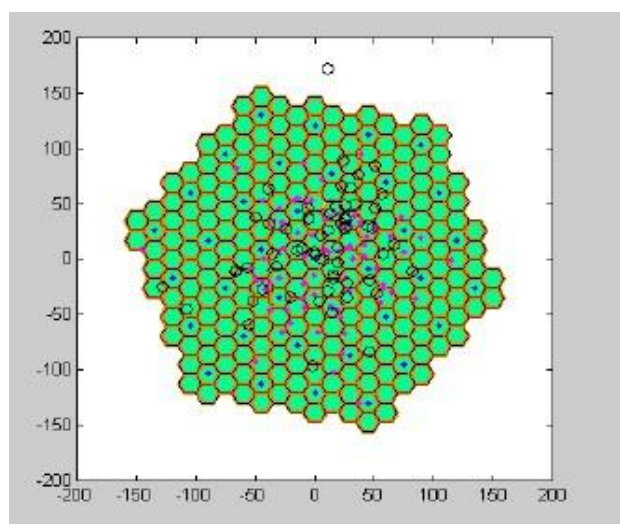

Fig. 1. Topology structure of macrocell and femtocell
Fig. 2 shows the flow chart of the modified algorithm. First, the RSS of the serving Base Station (BS) is measured either HeNB or eNB. Then the RSS measured is compared with the threshold if the serving BS is eNB or HeNB. If the result is follow the condition, then the velocity is measured. If the velocity is below $30 \mathrm{~km} / \mathrm{h}$, the handover will be executed to femtocell. If the two conditions above are not satisfied, it will handover from macocell to macrocell or macrocell to femtocell. In this proposed algorithm, the high speed users are not allowed to handover from macrocell to femtocell accordingly.

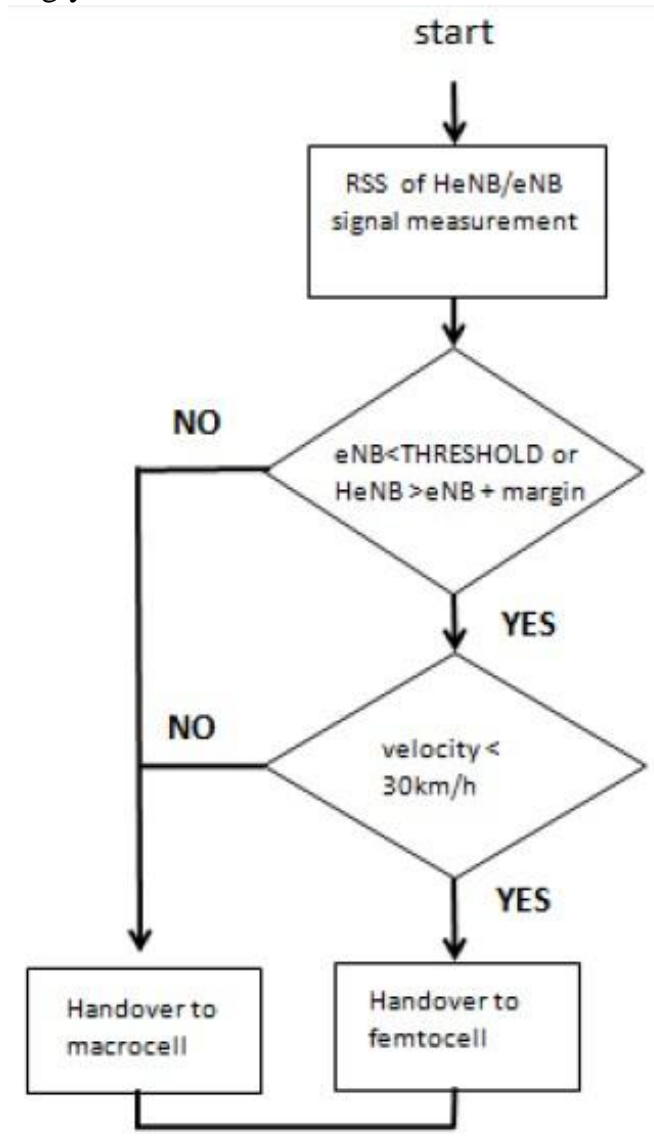

Fig. 2. Flow chart of the modified algorithm

\section{Performance Evaluation}

The simulation parameters used based on the 3GPP LTE standard [1]-[3]. The related parameters are listed below as shown in Table I.

In this section, we provide a comprehensive evaluation for the number of handover and the number of dropcall versus velocity of UE. In simulation scenario, 70 UEs and 60 femtocell was generated randomly across the macrocell coverage area for speed from $10 \mathrm{~km} / \mathrm{h}$ to $80 \mathrm{~km} / \mathrm{h}$. The simulation was run with 2000 time for each UE. Fig. 3 shows that the numbers of handover versus the velocity of UE from $0 \mathrm{~km} / \mathrm{h}$ to $80 \mathrm{~km} / \mathrm{h}$ for two different values of threshold. We decided to choose $-90 \mathrm{~dB}$ and $-100 \mathrm{~dB}$ as our preset threshold value for this research. From this figure, it can be seen that when the velocity of UE increased, the number of handover for both values were increased in the value of velocity from $10 \mathrm{~km} / \mathrm{h}$ to $20 \mathrm{~km} / \mathrm{h} /$. At $30 \mathrm{~km} / \mathrm{h}$ to $80 \mathrm{~km} / \mathrm{h}$, the handover call for higher speed user has decreased as compared to slow speed user. 
TABLE I: SIMULATION TABLE

\begin{tabular}{ll}
\hline \multicolumn{1}{c}{ Parameter } & \multicolumn{1}{c}{ Assumption } \\
\hline Celular layout & $\begin{array}{l}\text { Hexagonal grid, } 37 \text { clusters, } 7 \\
\text { cells per cluster }\end{array}$ \\
Cell radius & $2000 \mathrm{~m}$ \\
Propagation model & Okumura Hata Model \\
Traffic load & Voice traffic \\
Path loss (microcell) & $15.3+37.6 \log _{10}(\mathrm{R}[\mathrm{m}])+\mathrm{W}_{\mathrm{L}}$ \\
$\begin{array}{l}\text { Path loss (femtocell) } \\
\text { Log-normal shadowing } \\
\text { standard deviation (macrocell) }\end{array}$ & $8 \mathrm{~dB}$ \\
$\begin{array}{l}\text { Log-normal shadowing } \\
\text { standard deviation (femtocell) }\end{array}$ & $4 \mathrm{~dB}$ \\
$\begin{array}{l}\text { BS TX power (macrocell) } \\
\text { MS TX power (femtocell) }\end{array}$ & $43 \mathrm{dBm}$ \\
\hline \hline
\end{tabular}

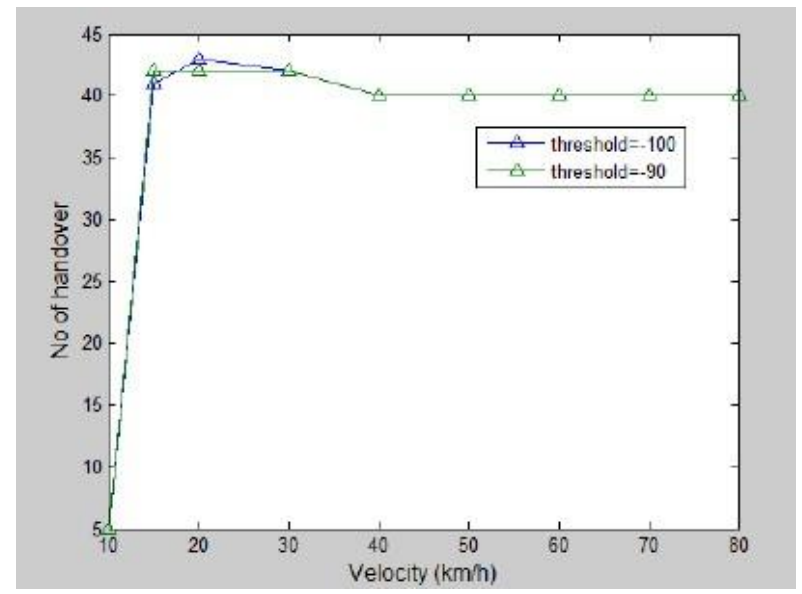

Fig. 3. No. of handover versus velocity with different threshold

In traditional UMTS handover algorithm, the high speed users and low speed users should not be have the same QoS when deploying the femtocell especially when the handover process occur from macrocell to femtocell. In the proposed algorithm, the high speed users from macrocell are not allowed handover to femtocell. Therefore, the proposed algorithm in this paper will reduce the unnecessary handover especially for the higher speed users. If the speed is above 30 $\mathrm{km} / \mathrm{h}$ the call will not be handover to the femtocell.

Fig. 4 illustrates that with the threshold preset, much dropcall happen for low speed user as compare to high speed UE. The $-90 \mathrm{~dB}$ threshold induces higher drop call as compared to $-100 \mathrm{~dB}$ threshold for high speed UE. From this result we can find that the threshold value should not be setting too late for high speed user as it will result more handover call and consequently causing higher drop call.

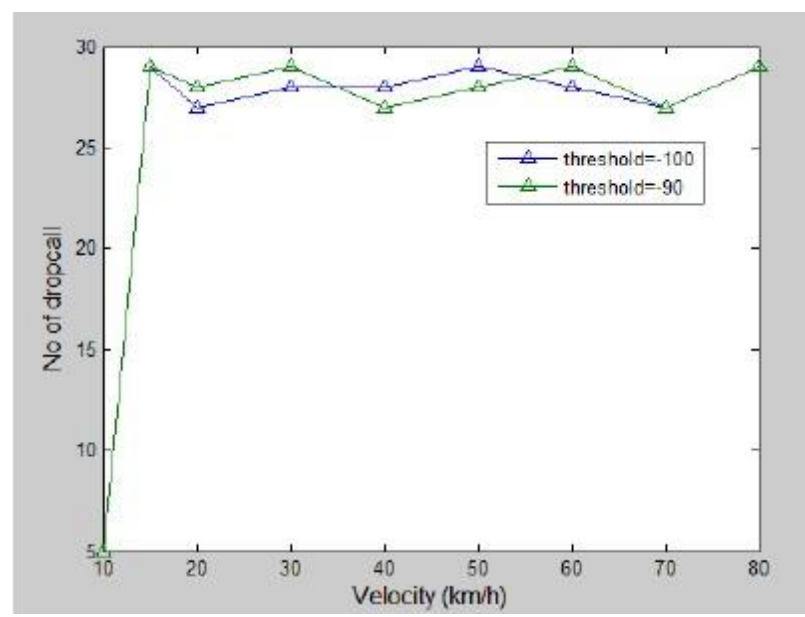

Fig. 4. No. of dropcall versus velocity with different threshold

The next figure shows the influence of margin setting on number of handover and drop call. Fig. 5 shows the number of handover is higher for the low speed user as compared to high speed user.

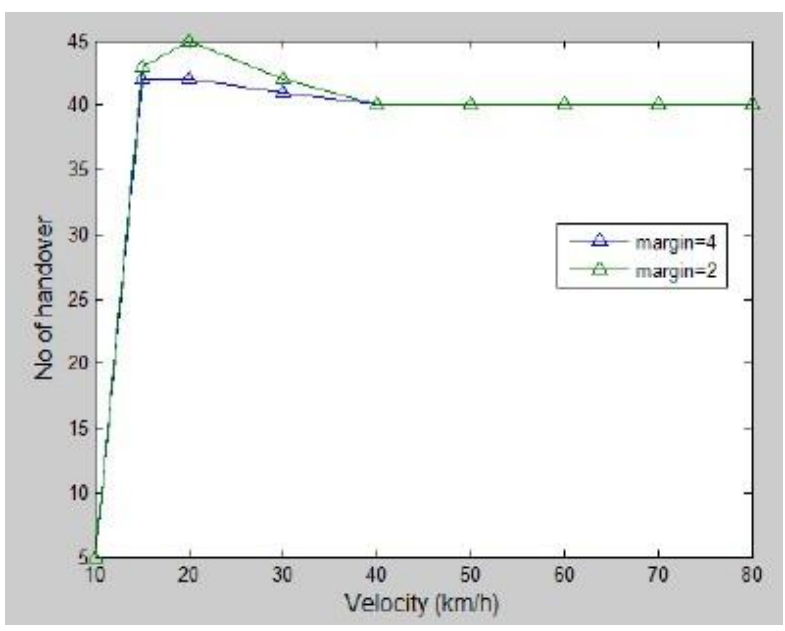

Fig. 5. No of handover versus velocity with different margin

Fig. 6 shows the number of drop call for $4 \mathrm{~dB}$ margin is higher as compared to $2 \mathrm{~dB}$ margin. The results prove the previous figures as it is not suitable to preset the same threshold value for low and high speed user.

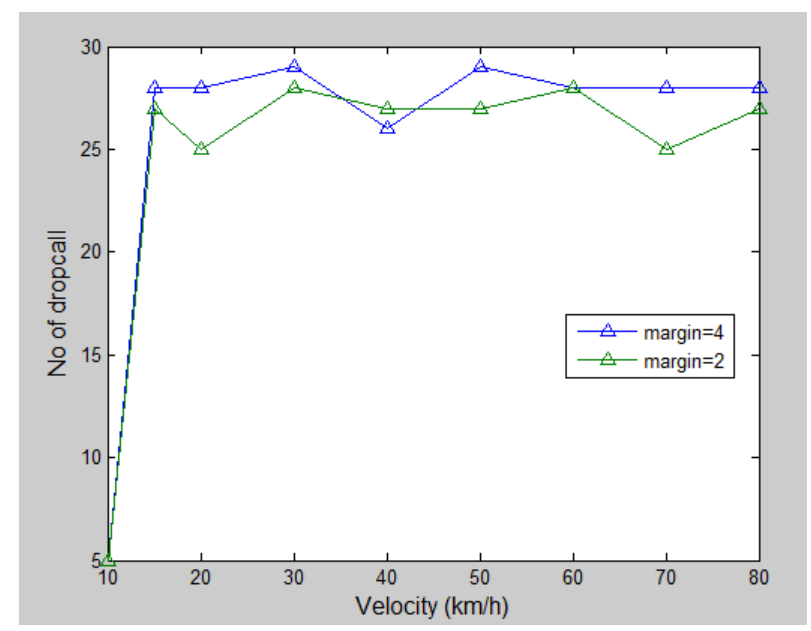

Fig. 6. No of dropcall versus velocity with different margin 


\section{CONCLUSIONS}

In this paper, modified handover procedure is presented with the deployment of femtocell in macrocell network. A handover procedure based on the UE's velocity has been studied. The results show that the high speed users and low speed users can not have the same threshold value when deploying the femtocell especially the handover from macrocell to femtocell. In this propose algorithm, we do not allow the high speed users handover from macrocell to femtocell. For future work, the velocity can be divide by 3 group which is below $15 \mathrm{~km} / \mathrm{h}$, between $15 \mathrm{~km} / \mathrm{h}$ and $30 \mathrm{~km} / \mathrm{h}$ and above $30 \mathrm{~km} / \mathrm{h}$ for different threshold setting value and classified user according to real time or not real time services Additionally, future research will focus on predicting the availability of neighboring cells willing to help in congested areas by developing a load balancing simulation environment.

\section{ACKNOWLEDGEMENT}

This paper is part of research work that supported by the e-Science grant no. 01-01-01-SF0407 funded by the Ministry of Science, Technology and Innovation and Faculty of Electrical Engineering, Universiti Teknologi MARA.

\section{REFERENCES}

[1] 3GPP TS 36.300 V11.5.0: Evolved Universal Terrestrial Radio Access (E-UTRA) and Evolved Universal Terrestrial Radio Access Network (EUTRAN), Overall description, March 2013.

[2] TS 36.331 3rd Generation Partnership Project, Technical Specification Group Radio Access Network, Evolved Universal Terrestrial Radio Access (E-UTRA), Radio Resource Control (RRC), Protocol specification (Release 8).

[3] TS 36.214, 3rd Generation Partnership Project; TS 36.331 3rd Generation Partnership Project; Technical Specification Group Radio Access Network, Evolved Universal Terrestrial Radio Access (E-UTRA), Physical Layer - Measurements (Release 8).

[4] S. Sesia, T. Issam, and P. J. B. Matthew, LTE-the UMTS Long Term Evolution: From Theory to Practice, Chichester: Wiley, 2011.

[5] K. A. Ali, H. S. Hassanein, H. T. Mouftah, "Directional cell breathing based reactive congestion control in wcdma cellular networks," in Proc 12th IEEE Symposium on Computers and Communications, ISCC 2007 pp. 685-690, July 2007.

[6] M. Zhang, W. Y. Li, S. Jia, L. Zhang, and Y. Liu, "A Lightly-loaded cell initiated Load Balancing in LTE self-optimizing networks," in Proc 2011 6th International ICST Conference on Communications and Networking in China (CHINACOM), pp. 421-425, Aug. 2011.

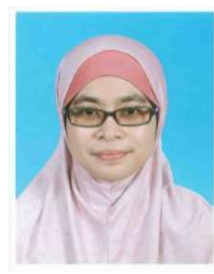

Azita Laily Yusof received her B.Eng degree from Universiti of Kebangsaan Malaysia (UKM), Malaysia in Electrical, Electronics \& System Engineering in 1999. She also obtained her M. Eng. degree from Universiti of Kebangsaan Malaysia (UKM) in Communication and Computer Engineering in 2000. In 2011, she was awarded a PhD degree in Electrical, Electronic \& Systems Engineering from Universiti Kebangsaan Malaysia (UKM), Malaysia specialization in Mobile Communication. She is currently a senior lecturer with the Department of Communication Engineering, Universiti Teknologi MARA (UiTM). Her current research interests include radio resource management and interference management in mobile communications networks. She is also the member of Wireless Communication Technology Group (WiCoT) at UiTM and a member of the IEEE Communications Society. She is also as Secretary, Registration Chair and Track Chair of the 2012 and 2013 IEEE Symposium on Wireless Technology \& Applications (ISWTA).

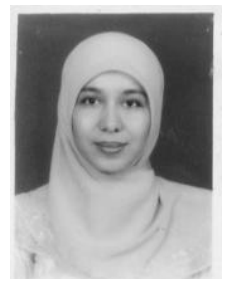

Norsuzila Ya'acob received her B.Eng degree from University of Putra Malaysia (UPM), Malaysia in Electronics \& Computer Engineering in 1999. She also obtained her M. Sc degree from University Putra Malaysia (UPM) in Remote Sensing and Geographic Information Systems in 2000. In 2011, she was awarded a PhD degree in Electrical, Electronic \& Systems Engineering from Universiti Kebangsaan Malaysia (UKM), Malaysia for a work on Modelling and Determination of Ionospheric Effects to Improve GPS System Accuracy. She is currently a Associate Professor with the Department of Communication Engineering, Universiti Teknologi MARA (UiTM). She is also the group leader of Wireless Communication Technology Group (WiCoT) at UiTM and a member of the IEEE Communications Society. She is also as Secretary, Registration Chair and Publication Chair of the 2011, 2012 and 2013 IEEE Symposium on Wireless Technology \& Applications (ISWTA). She was awarded "Hadiah Penerbitan ANGKASA 2010" from ANGKASA and MOSTI. She has published over 120 journal papers and conferences proceding on various topics related to Satellite, Space Weather, Remote Sensing and Mobile Communication. She also has filled 1 patent applications on Satellite. Thus far, her chapter InTech in the book "Trends in Telecommunications Technologies has so far been accessed 6000 times from top country. Her research interests include Satellite, Space Weather, Remote Sensing, Mobile Communication and Signal Processing. Email: norsuzilayaacob@yahoo.com, norsuzila@salam.uitm.edu.my.

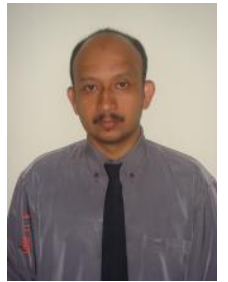

Mohd Tarmizi Ali is a Assiociate Professor at the Microwave Technology Center (MTC) of the Universiti Teknologi MARA (UiTM). He is also the group leader of Antenna Research Group at UiTM. He is a member of the IEEE and Secretary for AP/MTT/ECM Joint Chapter. He is also as Chair and Technical Program Chair of the 2011 \& 2012 IEEE Symposium on Wireless Technology \& Applications. He has been very promising as a researcher, with the achievement of several International Gold Medal awards, a Best Invention in Telecommunication award and a "Special Cancellor Award" from Universiti Teknologi Malaysia (UTM) for his research and innovation. He has been awarded "Postgraduate Best Student Award 2011" from UTM. His professorial interests include the areas of communication antenna design, radio astronomy antennas, satellite antennas, and electromagnetic radiation analysis. He has published over 100 journal papers and conferences proceding on various topics related to antennas, microwaves and electromagnetic radiation analysis. He also has filled 5 patent applications on communication antennas. Thus far, his publications have been cited 237 times, and the H-index is 8 (Source: Google Scolar). He is now handling many research projects from the Ministry of Science, Technology and Innovation (MOSTI) and Ministry of Higher Education Malaysia (MOHE). 